\title{
Discussion about Enterprises Environmental Cost Management and Control Based on the Concept of Ecological Civilization
}

\author{
Wei Li, Jinglu Jiang \\ School of Economics and Management, \\ Northeast Dianli University, \\ Jilin, China
}

\begin{abstract}
According to statistics, the word "environment" and "ecology" appears respectively 25 times and 39 times in the report of the 18th National Congress of the Communist Party of China which discusses the need to vigorously promote the construction of ecological civilization, emphasizes efforts to build a beautiful China to achieve sustainable development of the Chinese nation. The report for the first time discussed the construction of ecological civilization at the height of the overall layout. These play an important role from a deeper meaning for building and improving environmental cost accounting system in our country. As the enterprise gradually set up environmental protection consciousness, the requirement for environmental cost management and control becomes more urgent. Based on the analysis of definition and classification of environmental cost, this paper puts forward new requirements for it from the perspective of ecological civilization, points out some problems existed in our country enterprise environment cost management and control, and presents relevant ideas and suggestions based on the concept of ecological civilization. It provides the reference for the enterprises to realize coordinated development among ecological benefits, economic benefits, and social benefits.
\end{abstract}

Keywords-ecological civilization; environmental cost management and control; ecological benefits; economic benefits

\section{I.INTRODUCTION}

\section{A. Definition of environmental cost}

Up to now, there has been no uniform concept defining environmental cost. However, according to "Position Statement of Accounting and Financial Reporting for Environmental Cost and Liabilities" adopted by UN Group of Governmental Experts of the International Standards of Accounting and Reporting in 1998, environmental cost refers to additional expenditure caused by enterprises' attempt to reduce negative effect of producing activities on environment [1]. The definition views the load cost which enterprise impact on environment and preventive measures expenses as accounting object, presents the environmental cost goal is to manage the environmental impact caused by enterprises activities, and implement the requirements meet by environmental objectives.
According to the present situation of our country, the implications of enterprise environment cost should be explained taking environmental protection as the starting point, and taking the concept of ecological civilization as a guide. All the factors that affect the environment are attributable to environmental cost in the enterprise entire production process, including the cost and recovery of natural resources, investment in environmental protection equipment, the cost of measures against environmental pollution caused by enterprises activities, the environmental pollution cost of waste discharge caused by the negative externalities.

\section{B. Classification of environmental cost}

According to the implications of environmental cost, environmental cost can be divided into narrow sense and broad sense environment cost. The former is the cost of enterprise for the recovery and improvement of environmental conditions, the latter includes the narrow sense environment cost and the cost of natural resources consumed by the enterprise, the environmental pollution cost burden on society, namely the negative externality costs.

According to the spatial extent of occurrence, the environmental costs can be divided into internal and external environmental costs. The motivation of external environment cost is the enterprise. Under the guidance of the concept of ecological civilization, this part of the cost will be gradually transformed into the internal environment cost which is consistent with the matching principle in accounting.

\section{NEW REQUIREMENTS OF ENTERPRISE} ENVIRONMENTAL COST MANAGEMENT AND CONTROL

Ecological civilization is in the succession of industrial civilization developed and abandoned its cruelty and harmfulness, and absorbed the beneficial aspects of agricultural civilization. It is the critique and sublation of various kinds of civilization in human history. Harmony and coordination is the essential feature of the ecological civilization, which has a high degree of internal consistency with scientific outlook on development. For enterprise environmental cost management and control, the concept of ecological civilization means to not only realize their economic benefits in this process but also focus on certain ecological and social benefits. Not only is 
the requirement of entire social sustainable development strategy, but also the performance of enterprises to fulfill their social responsibility.

According to the principle of effective control and cost-effectiveness, new requirements for environmental cost management and control based on the new concept of ecological civilization can be summarized as follows: to realize comprehensive, sustained and effective control of environmental cost, namely to achieve coordination and a win-win situation among ecological benefits, economic benefits and social benefits.

\section{EXISTING PROBLEMS OF ENTERPRISE ENVIRONMENTAL COST MANAGEMENT AND CONTROL}

\section{A. Lack of scientific standards of management and control}

Enterprise environmental cost management and control should be goal oriented and take each production link as the key. Enterprises' behavior of management and control should reasonably penetrate the formative process of environmental cost, consider the various factors affecting the environment cost, and control it in a pre-set range. Scientific standards of management and control play an important role in the subsequent course of business. Currently, the standards that manage and control enterprise environmental cost has not yet formed, which will adversely affect the smooth implementation of the follow-up work [2].

B. Related laws and regulations are not perfect, the subject of environmental cost control is not clear

The coverage of a series of environmental laws and regulations formulated by the government is not comprehensive, but also the implementation details needs to be improved. The "accounting standards for business enterprises" implemented in our country does not include the environmental accounting, and has not yet formed a specialized or independent environmental accounting standards. Relevant provisions scattered in fixed assets, biological assets, contingencies, oil and gas extraction, the presentation of financial statements and other specific criteria. Regulatory environmental accounting elements are only the environmental matters which can be determined and measured; the other issues are not included in the criteria range. This makes enterprises overlook the important factors in the actual management and control of the environmental cost, which is lack of comprehensive and systematic.

Energy resource cost and waste emissions almost exist in each link of enterprise production and management. However, in addition to the relevant departments carry out a certain degree of supervision and enterprises bear part of control, the negative externality of environment cost cannot be reasonable control because of the lack of clear control subjects [3].
C. Ignore the ecological philosophy, environmental cost management focus on the end of treatment

Due to neglect the environmental friendly concept of eco-oriented operating, operators do not really care about environmental issues. It is difficult to consider the development of enterprises from the perspective of environmental protection. Enterprise environmental impact is not important to the related to corporate image, then affecting the core competitiveness of the enterprise level. Managers are difficult to consciously raise the level of environmental protection requirements above the national level. Since the operating system is not a reasonable, internal environmental management department cannot provide clear environmental cost analysis data for accounting department, then affecting the reliability of cost data. The number of enterprises which implement the environmental cost management and control is relatively small, most of them take remedial measures after an adverse impact on the environment which is welcomed by enterprises because this mode generally does not affect the normal production and operation of enterprises. However the ex-post governance principle weakens the effect of environmental prevention costs which has the risk of uncontrolled environmental cost management. It is not conducive to the sustainable development of enterprises.

D. Property right of environmental resources and the scope of environmental cost management and control are not clear

For a long time, our country exists a phenomenon that the environment resource property is not clear or multiple, the ownership and the rights to use environmental resources are confused, resulting in a waste of resources and destruction. The consequence of unclear property is that there are no active economic agents to bear the losses caused by environmental degradation. Free use of environmental resources resulted in unclear scope of environmental cost management and control.

IV. POLICY RECOMMENDATIONS OF IMPROVING ENTERPRISES ENVIRONMENTAL COST MANAGEMENT AND CONTROL

\section{A. Develop appropriate standards of environmental cost management and control}

From the micro level, the historical cost analysis method can be used in enterprises. Enterprises take environmental cost which is the best level in history record as the reference standard. This method is suitable for enterprises which have been operating for many years and cost data are more complete. Because the reference is the optimal level in the history, this standard is reasonable and can be reached through the comparison and modification by the relevant departments.

From the meso-level, an industry can determine its standard by analyzing relevant indicators in advanced enterprises. In the case of some enterprises with similar external conditions, an industry can refer to the 
advanced indicators of environmental cost management and control, and amend it according to the actual status of the industry, making it suitable for the development level of the industry.

From the macro level, the relevant government departments can use the weight coefficient method to analysis the industry indicators. According to the degree of industry impact on the environment, government departments determine the weight coefficient of each industry and determine the standards of environmental cost management and control according to the impact on the environment of different industries in the same time.

\section{B. Improve environmental protection laws and regulations, establish monitoring mechanisms and clear subject of environmental cost control}

In order to regulate corporate environmental behaviors and protect the public interest, government needs to improve the relevant environmental laws and regulations, establish monitoring mechanisms and quantitative management system of sewage, implement swiping card to supervise the enterprises' behavior. It is necessary to implement the responsibility system for environmental protection target to assess enterprise, develop environmental accounting standards to stipulate the measurement, record, report and procedure of environmental cost, clear subject of environmental cost control, and strengthen the disclosure of environmental cost information. This will help managers to put environmental cost management and control into the corporate development strategy which will realize the coordinated development of ecological benefits, economic benefits, and social benefits.

\section{Establish ecological management system and implement cycle management}

The concept of ecological civilization will guide enterprises to form the ecological management consciousness, then establishes ecological management system, and implement the periodic comprehensive management of environmental cost, This management model includes prior-control, in-process control, and exproduct control of cost to accomplish the target cost as shown in Figure 1.

The factor of environmental cost should be considered in all stages of production and operation which includes the cost forecast and plan of product design, raw material procurement in the pre link, the control and accounting of environment cost in the link of production and sales, and the assessment and analysis of the environmental cost in the link of recycling and disposal. According to actual situation, enterprises should establish ecological management strategy, set up environmental management organizations, and manage environmental cost periodically.

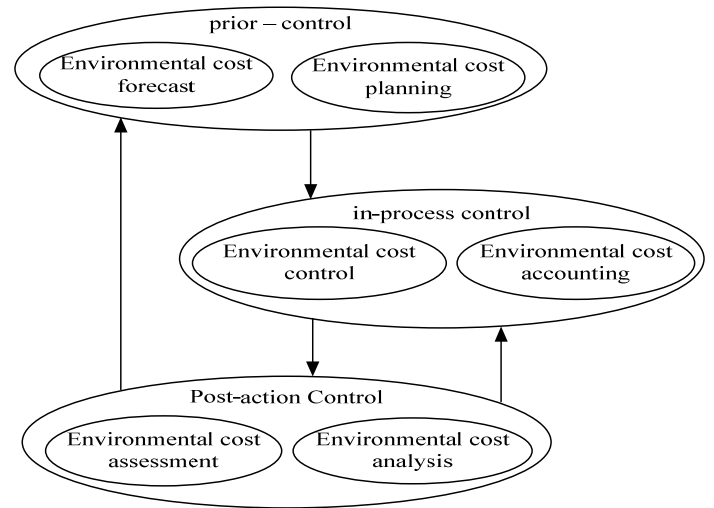

Figure 1. Management model

D. Establish the concept of ecological civilization and clarify the definition of environment resource property

Ecological civilization is the embodiment of social civilization including the Scientific Outlook on Development and socialist core values. Environmental cost management and control should be based on the concept of ecological civilization. Only by combining the growth of enterprises and the construction of ecological civilization, can make the future of enterprises development is sustainable. In order to guide the enterprises' economic behavior complying with more ecological civilization, the government must clarify the definition of environment resource property, use rights and other rights of environmental resources, and use the legal form to monitor and protect them. It is necessary to develop environmental resource property in the market, protect interests of property rights, and develop relevant incentive mechanism [4].

\section{CONCLUSIONS}

As people concern about environment continues to improve, as well as increasingly sophisticated environmental regulations, the environmental cost issues of enterprises will be increasingly prominent. It is not only related to the profitability of the company, but also affects the survival and development of enterprises. Enterprises should establish the concept of ecological civilization, balance local interests and overall interests, short-term interests and long-term interests, strive to carry out eco-friendly oriented management. At the same time, effective measures of environmental cost management and control should be taken. Not only can reduce environmental costs, but also can assume social responsibility of protect the environment, which unify ecological benefits, economic benefits, and social benefits, achieving “win-win” development ultimately. 


\section{REFERENCES}

[1] Wang Xiao-yan, Business environmental cost control from the perspective of circular economy. Modern Finance Economics, (2), pp. 41-46, 2009.

[2] Wang Ying, Enterprises environmental cost and its control in China. Journal of Business Research, (7), pp. 166-174, 2010.
[3] Liu Jin-bin, Explore the multi-dimensional environmental cost control systems. Journal of Finance and Management. (7), pp. 9394, 2010.

[4] Liu Li-min, Environmental cost control under the extension of the production responsibility system, Metallurgical Industry Press, Beijing, pp. 21-24, 2010. 